\title{
Thermoluminescence response of electron and photon irradiated Zinc Borate Silica (ZBS) host glass system
}

Respuesta de termoluminiscencia del sistema de vidrio anfitrión de silice

borato de zinc (ZBS) irradiado con electrones y fotones

Autor:

Bahra Mohammed (1) (3)

M. S. Jaafar ${ }^{(1)}$

H. Wagiran ${ }^{(2)}$

\section{ARTÍCULO DE INVESTIGACIÓN} CIENTÍFICA Y TECNOLÓGICA

How to cite this paper:

Mohammed. B., Jaafar. M. S., Wagiran. H., Thermoluminescence response of electron and photon irradiated Zinc Borate Silica (ZBS) host glass system. Innovaciencia Facultad de Ciencias Exactas, Naturales y Agropecuarias. 2018; 6(1) S1: 1-6.

Reception date:

Received: 15 August 2018

Accepted: 25 November 2018

Published Online: 28 December 2018

DOI:

http:/ /dx.doi.org/10.15649/2346075X.484

\section{ABSTRACT}

Introduction: Glass phosphors are broadly used to determine patient doses in radiation diagnostic and radiotherapy because of their good features, the dose ranges of interest are approximately 0.1 -100 mGy for clinical x-ray diagnostics, and 1-5Gy for radiotherapy. Materials and Methods: Borate silica glass samples were prepared using melt quenching technique, XRD analysis confirms that the glass system is amorphous (non- crystalline). TL properties of glass were investigated such as optimum concentration, heating rate, and annealing procedure. The optimum glass samples of $45 \mathrm{ZnO}-45 \mathrm{~B}_{2} \mathrm{O}_{3}-10 \mathrm{SiO}_{2}$ are used as glass radiation dosimeter. The samples were irradiated using $6 \mathrm{MeV}$ and $6 \mathrm{MV}$ photon beams in a dose range (0.5-4) Gy. Results and Discussion: There is single and wide thermoluminescence glow curve that offering with maximum intensity at about $165^{\circ} \mathrm{C}$. Linear dose-response behavior has been observed in this dose range for both irradiation electron and photon beam. Sensitivity and minimum detectable dose have been found. The sensitivity of $6 \mathrm{MeV}$ is 1.7 greater than the sensitivity of 6MV photon energy. Conclusions: The results point out that this glass has the potential to be used as an electron and photon radiation dosimeter.

Keywords:

Thermoluminescence dosimetry, Borate silica, Electron and photon TLD glass irradiation.

\footnotetext{
Radiation and Medical Physics, Research Group, School of Physics, Universiti Sains Malaysia, 11800, Pulau Penang, Malaysia, bahra noori@soran.edu.iq

(2) Department of Physics, Universiti Teknologi Malaysia, 81310 Skudai, Johor, Malaysia

(3) General science Department, Faculty of Education, Soran University, Kurdistan Region, Irac
} 
INTRODUCTION

Different types of TLDs which are most accepted in the field of radiation protection and medical dosimetry used to determine the energy response of electron and photon ${ }^{(1-4)}$. Glass phosphors are broadly used to determine patient doses in radiation diagnostic and radiotherapy because of their good features, the dose ranges of interest are approximately 0.1 -100 mGy for clinical x-ray diagnostics, and 1-5Gy for radiotherapy ${ }^{(5,6)}$. The Characteristics of these glasses phosphor doped with several elements were prepared by the melt quenching method and irradiated with photons and electron to doses in the 0.5-4.0 Gy range. Glowing curves, dose response, reproducibility of the response, dose threshold and thermal fading were studied $\stackrel{(6-8)}{ }$. To improve the TL properties, many researchers attempt to find new materials and compositions for using as TL dosimeter in radiation protection and medical dosimetry fields. Our search is an attempt to find out the characteristics of new glass host to know the effect of different kinds of energies on this pure compound (ZBS) as TL dosimetry without any activator, such as the glow curve, dose response, sensitivity to radiation, and minimum detectable dose (MMD), when subjected to different kinds of energies.

\section{MATERIALS AND METHODS}

A $99.5 \%$ purity of silica oxide prepared using the Rice Husk that obtained from a Malaysian domestic procurement and processing of paddy and rice (BERNAS) ${ }^{(9)}$. Glass system was prepared according to following composition (90-x) $\mathrm{ZnO}-\mathrm{xB}_{2} \mathrm{O}_{3}$ $10 \mathrm{SiO}_{2}$, where $\mathrm{x}=25,30,35,40,45,50 \mathrm{~mol} \%$ using melt quenching technique inside the electronic furnace ( Nabertherm more than $30-3000{ }^{\circ} \mathrm{C}$ ) with high temperature $1300{ }^{\circ} \mathrm{C}$ for 1 hour. Melting mixture taken out and poured on stainless steel inside other furnace and annealed at $400 \mathrm{oC}$ for 4 hours to avoid the thermal stress. Glass cut to small size as TLD and weighted by using an analytical balance Presica XT 220A. Model Harshaw 4500 TLD reader was used to read out the TL yield at physics laboratory in University Technology Malaysia at Johor Bahru, to hold back possible false light signals from triboluminescence as well to reduce oxidation of the heating element, the nitrogen atmosphere was used. Every data point in this work represented an average of 3 individual TL glass reading. Un-doped borate silica glass samples (ZBS) were prepared with varying mol percentage of zinc oxide (according to the amount in Table.1) and exposed to 50Gy cobalt-60 gamma radiation to study the characteristics of this glass samples $\stackrel{(10)}{ }$.

Table1. The raw materials and chemical compositions of prepared Un-doped glasses.

\begin{tabular}{cccc} 
& \multicolumn{3}{c}{ Batches Composition $(\mathrm{mol} \%)$} \\
\cline { 2 - 4 } Samples & $\mathrm{ZnO}$ & $\mathrm{B}_{2} \mathrm{O}_{3}$ & $\mathrm{SiO}_{2}$ \\
S1 & 65 & 25 & 10 \\
S2 & 60 & 30 & 10 \\
S3 & 55 & 35 & 10 \\
S4 & 50 & 40 & 10 \\
S5 & 45 & 45 & 10 \\
S6 & 40 & 50 & 10 \\
\hline
\end{tabular}

The optimum sample $45 \mathrm{ZnO}-45 \mathrm{~B}_{2} \mathrm{O}_{3}-10 \mathrm{SiO} 2$ was irradiated with $6 \mathrm{MeV}$ and $6 \mathrm{MV}$ from (0.5-4) Gy using linear accelerator (LINAC), Elekta PRECISE, provided by Department of Radiotherapy and Oncology, Pantai Hospital, Palau Penang. Beam field size set up was $10 \times 10 \mathrm{~cm} 2$ and the samples were placed (on the surface 
of a solid phantom) at standard source surface distance (SSD) for $100 \mathrm{~cm}$. $400 \mathrm{MU} / \mathrm{min}$ a constant dose rate was used and the delivered doses of the machine from (50 to 400) MU (monitor unit).

\section{RESULTS}

Fig.1 and Fig. 2 show the glow curve and TL response glass (ZBS) with different concentration of ZnO. The highest TL intensity was set up to be that sample with $45 \mathrm{~mol} \% \mathrm{ZnO}$ and The glow curves have defined the shape.

Fig. 1: The intensity of (ZBS) with various $\mathrm{ZnO} \%$

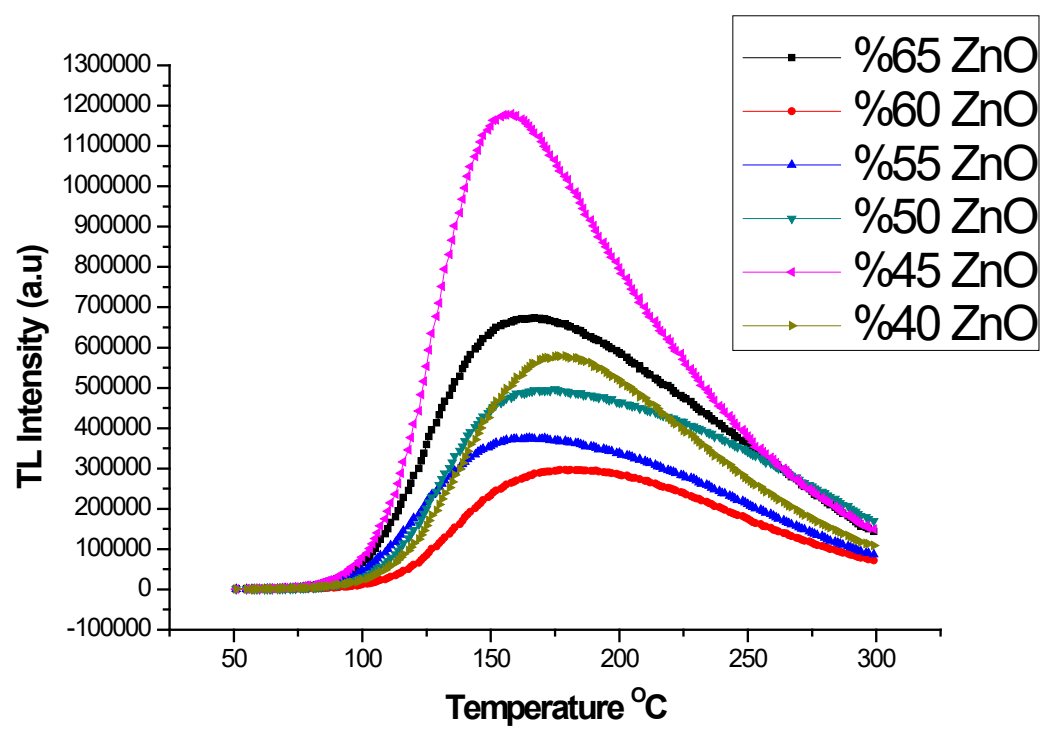

Fig. 2: TL response of (ZBS) with various $\mathrm{ZnO} \%$

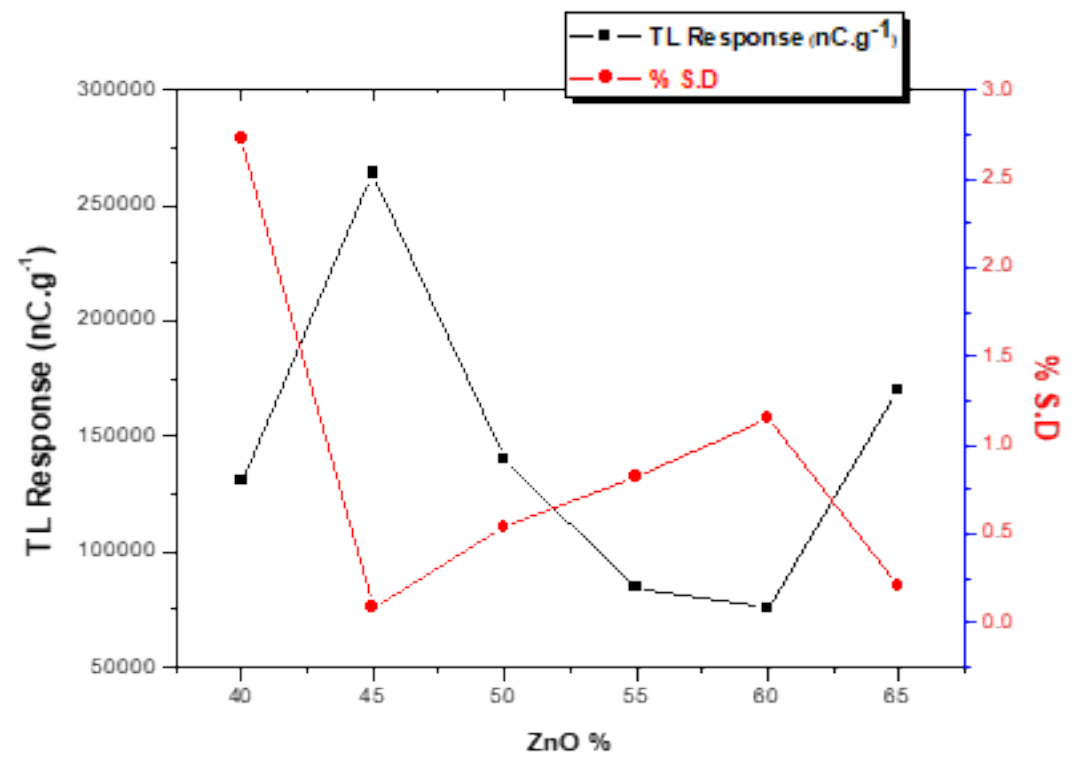


The plotting intensity of luminescence as a function of temperature is called glow curve of thermoluminescence. The response of the TLD material represents by the area under the curve and expresses the radiation energy. fig 3 illustrates the glow curve glass samples $45 \mathrm{ZnO}-45 \mathrm{~B}_{2} \mathrm{O}_{3}-10 \mathrm{SiO}_{2}$ irradiated with dose $4 \mathrm{~Gy}$ for both $6 \mathrm{MeV}$ electron and $6 \mathrm{MV}$ photon beams.

Fig. 3: ZBS glass glow curve irradiated with $6 \mathrm{MeV}$ and $6 \mathrm{MV}$

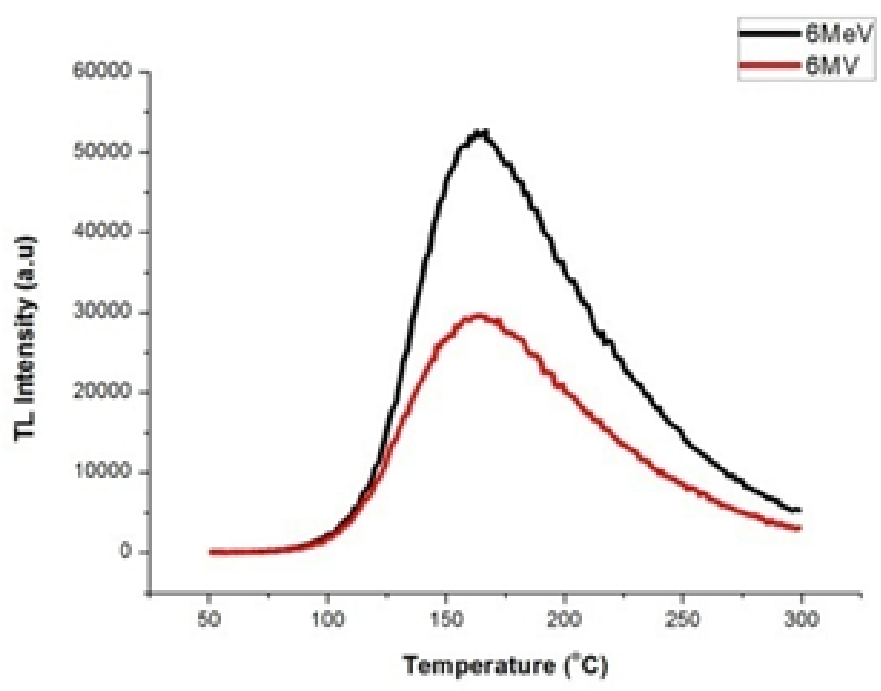

To study the dose response of the glass sample ( $\mathrm{ZBS}) 45 \mathrm{ZnO}-45 \mathrm{~B}_{2} \mathrm{O}_{3}-10 \mathrm{SiO}_{2}$, the samples subjected to $6 \mathrm{MeV}$ and $6 \mathrm{MV}$ at a range of (0.5-4) Gy as shown in fig 4. It seems that the beam of $6 \mathrm{MeV}$ and $6 \mathrm{MV}$ rising when the dose range elevated gradually for both types of radiations, this means that the TL response of the samples is dose-dependent.

Fig. 4: ZBS glass dose response irradiated with $6 \mathrm{MeV}$ and $6 \mathrm{MV}$

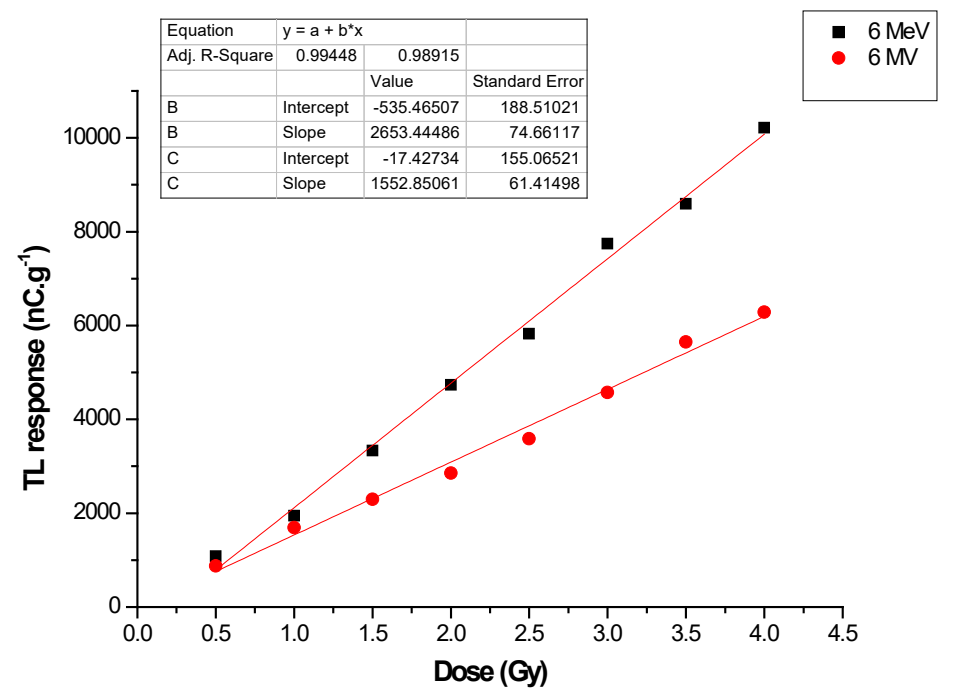


From fig 4, the sensitivity of the data point for samples can be determined by the slope of the plotting TL response as a function of dose.

The lower limit of detection is important in low dose measurement where the signal of an irradiated TLD is almost the same as the background. The Minimum Detectable Dose was determined according to the following expression Eq. 1. (11)

$$
\mathrm{D}_{\mathrm{o}}=\left(\mathrm{B}^{*}+2 \sigma_{\mathrm{B}}\right) \mathrm{F}
$$

where Do is the minimum detectable dose, $\mathrm{B}^{*}$ is the average background TL of the unirradiated dosimeter. $\sigma \mathrm{B}$ is the standard deviation of the background signal, and $\mathrm{F}$ is the calibration factor expressed in $\mathrm{Gy} \mathrm{nC}-1$ Eq. 2

$$
\mathrm{F}=\frac{\operatorname{dose}(\mathrm{Gy})}{\mathrm{A}(\mathrm{nC})}
$$

\section{DISCUSSION}

Defined glow curve shape and the high TL intensity displayed by the basic compound of ZBS indicated that the materials intrinsic are enough to traps and center of recombination electrons and holes. Single glow curve for both $6 \mathrm{MeV}$ and $6 \mathrm{MV}$ ) that drop out after maximum intensities at around 165 oC. Samples show off that the TL response to a dose form $6 \mathrm{MeV}$ was higher than the same dose from $6 \mathrm{MV}$ beams. The result of glow curve indicated that borate silica glass has a good response for $6 \mathrm{MeV}$ and $6 \mathrm{MV}$. From Fig 4, it seems that the beam of $6 \mathrm{MeV}$ and $6 \mathrm{MV}$ rising when the dose range elevated gradually for both types of radiations, this means that the TL response of the samples is dose-dependent. The sensitivity of $45 \mathrm{ZnO}-45 \mathrm{~B}_{2} \mathrm{O}_{3}-10 \mathrm{SiO}_{2}$ glass sample is $2653\left(\mathrm{nC} \cdot \mathrm{Gy}^{-1} \cdot \mathrm{g}^{-1}\right)$ and $1552\left(\mathrm{nC} \cdot \mathrm{Gy}^{-1} \cdot \mathrm{g}^{-1}\right)$ for $6 \mathrm{Me}-$ Vand 6MV photon beams respectively, the response dose of sample irradiated with $6 \mathrm{MeV}$ has sensitivity 1.7 times higher than the sample irradiated with 6 MV photon in the same condition. The minimum detectable dose (MDD) for the present glass samples subjected to $6 \mathrm{MeV}$ and $6 \mathrm{MV}$ are $40 \mathrm{mGy}$ and $34 \mathrm{mGy}$ respectively.
The TL properties of zinc borate silica were investigated. The results show the linear dose response for the range ( 0.5 to 4$) \mathrm{Gy}$. The glow curve of proposed samples is single and board that falls after maximum intensity at $165 \mathrm{oC}$. The sensitivity of the data point for samples can be determined from the slope of the plotting, TL response as a function of dose the response dose of the sample irradiated with $6 \mathrm{MeV}$ has sensitivity 1.7 times higher than sample irradiated with a $6 \mathrm{MV}$ photon. Minimum detectable dose determined. This finding indicated that the present glass system is suitable to be used as thermoluminescence dosimeter particularly for an electron irradiation. 


\section{REFERENCES}

1. Bahri Ttk, Wagiran H, Hussin R, Saeed M, Hossain I, Ali H. Dosimetric Properties of Germanium Doped Calcium Borate Glass Subjected To $6 \mathrm{mv}$ And $10 \mathrm{mv}$ X-Ray Irradiations. Nuclear Instruments and Methods in Physics Research Section B: Beam Interactions with Materials And Atoms. 2014b; 336:70-3.

2. Hossain I, Wagiran H, Yaakob N. Thermoluminescence Of Ge-And Al-Doped Sio2 Optical Fibers Subjected To 0.2-4.0 Gy External Photon Radiotherapeutic Dose. Journal of Applied Spectroscopy. 2013; 80(4):620-3.

3. Wagiran H, Hossain I, Bradley D, Yaakob A, Ramli T. Thermoluminescence Responses Of Photon And Electron Irradiated Ge-And Al-Doped Sio2 Optical Fibres. Chinese Physics Letters. 2012; 29(2):027802.

4. Yaakob N, Wagiran H, Hossain I, Ramli A, Bradley D, Hashim S, Et Al. Electron Irradiation Response On Ge And Al-Doped Sio 2 Optical Fibres. Nuclear Instruments and Methods In Physics Research Section A: Accelerators, Spectrometers, Detectors And Associated Equipment. 2011; 637(1):185-9.

5. Icru Fq. Units for Ionizing Radiation. Icru Report. 1998; 60.

6. Alajerami Ysm, Hashim S, Ramli At, Saleh Ma, Saripan Mi, Alzimami K, Et Al. Thermoluminescence Responses Of Photon-And Electron-Irradiated Lithium Potassium Borate Co-Doped With $\mathrm{Cu}+\mathrm{Mg}$ Or Ti+ Mg. Applied Radiation And Isotopes. 2013; 78:21-5.

7. Lim Ty, Wagiran H, Hussin R, Hashim S. Thermoluminescence Response Of Dysprosium Doped Strontium Tetraborate Glasses Subjected To Electron Irradiations. Applied Radiation and Isotopes. 2015; 102:10-4.

8. Aboud H, Wagiran H, Hussin R, Ali H, Alajerami Y, Saeed M. Thermoluminescence Properties Of The Cu-Doped Lithium Potassium Borate Glass. Applied Radiation and Isotopes. 2014; 90:35-9.
9. Bahra N, Jaafar M, Iskandar S, Cheng S. Effect Of Different Concentrations Of Doped Rare Earth Element On Borate-Silica Oxide Glass Structure. Journal of Optoelectronics And Biomedical Materials Vol. 2015; 7(2):47-52.

10. Bahra Mohammed Msj, H.Wagiran. Effect of $\mathrm{Cu} 2 \mathrm{o}$ on the Thermoluminescence Properties Of Zno-B2o3-Sio2 Glass Sample Journal Of Luminescence. 2017; 190: 228-33.

11. Furetta C. Handbook Of Thermoluminescence: World Scientific; 2003. 